ARTICLE

https://doi.org/10.1038/s41467-019-12513-x

\title{
Enhancing electron diffusion length in narrow- bandgap perovskites for efficient monolithic perovskite tandem solar cells
}

Zhibin Yang (1) ${ }^{1}$, Zhenhua Yu', Haotong Wei (1) ${ }^{1}$, Xun Xiao (1) ${ }^{1}$, Zhenyi Ni ${ }^{1}$, Bo Chen ${ }^{1}$, Yehao Deng ${ }^{1}$, Severin N. Habisreutinger (1) ${ }^{2}$, Xihan Chen (1) ${ }^{2}$, Kang Wang ${ }^{2}$, Jingjing Zhao ${ }^{1}$, Peter N. Rudd ${ }^{1}$, Joseph J. Berry (1) ${ }^{2}$, Matthew C. Beard ${ }^{2} \&$ Jinsong Huang (D) ${ }^{1 \star}$

Developing multijunction perovskite solar cells (PSCs) is an attractive route to boost PSC efficiencies to above the single-junction Shockley-Queisser limit. However, commonly used tin-based narrow-bandgap perovskites have shorter carrier diffusion lengths and lower absorption coefficient than lead-based perovskites, limiting the efficiency of perovskiteperovskite tandem solar cells. In this work, we discover that the charge collection efficiency in tin-based PSCs is limited by a short diffusion length of electrons. Adding 0.03 molar percent of cadmium ions into tin-perovskite precursors reduce the background free hole concentration and electron trap density, yielding a long electron diffusion length of $2.72 \pm 0.15 \mu \mathrm{m}$. It increases the optimized thickness of narrow-bandgap perovskite films to $1000 \mathrm{~nm}$, yielding exceptional stabilized efficiencies of 20.2 and $22.7 \%$ for single junction narrow-bandgap PSCs and monolithic perovskite-perovskite tandem cells, respectively. This work provides a promising method to enhance the optoelectronic properties of narrow-bandgap perovskites and unleash the potential of perovskite-perovskite tandem solar cells.

\footnotetext{
${ }^{1}$ Department of Applied Physical Sciences, University of North Carolina, Chapel Hill, NC 27599, USA. ${ }^{2}$ Chemistry \& Nanoscience Center, National Renewable Energy Lab, Golden, CO 80401, USA. *email: jhuang@unc.edu
} 
T he power conversion efficiencies (PCEs) of single junction perovskite solar cells (PSCs) have recently rapidly increased to $23.7 \%^{1-7}$, approaching the Shockley-Queisser limit ${ }^{8}$. To further enhance PCE of PSCs, an attractive route is to construct multijunction solar cells with multiple absorbing layers, which have complementary absorption spectra. Owing to the tunable bandgap and small open-circuit voltage $\left(V_{\mathrm{OC}}\right)$ deficit of perovskite materials ${ }^{9-11}$, they have been successfully coupled with other narrower bandgap semiconductors such as $\mathrm{Si}^{12-14}$, CIGS $^{15,16}$, semiconducting polymers ${ }^{17}$ and CZTSS $e^{18}$ to develop tandem solar cells. To date, the PCE of Si-perovskite tandem solar cells has reached certified value of $28.0 \%$, higher than the efficiencies of either single-junction perovskite or Si solar cells ${ }^{1}$. The wide bandgap tunability from 1.20 to $2.30 \mathrm{eV}$ allows the development of perovskite-perovskite tandem solar cells, which still enjoys the benefits of low-cost solution processing of perovskite materials. To date, both four-terminal and monolithic perovskite-perovskite tandem solar cells have been successfully developed. Im and coworkers reported the first monolithic perovskite-perovskite tandem cell with PCE of $10.4 \%$, and the PCE has been gradually increased to $21.0 \%^{19-23}$. Jen and coworkers reported the first four terminal perovskite-perovskite tandem cells with an efficiency of $19.1 \%^{24}$, and the efficiency has now gone up to $23.1 \%^{25}$.

From the perspective of cost, developing monolithic tandem cells is potentially more valuable. However, one main limitation for relatively low PCE of perovskite monolithic tandem solar cells comes from the poor semiconducting properties of Sn-based narrow-bandgap (NBG) perovskites. Till now, Sn substitution in $\mathrm{Pb}$-perovskites is the only approach to reduce the bandgap to as narrow as $1.20 \mathrm{eV}$. However, compared to $\mathrm{Pb}$-perovskites, $\mathrm{Sn}$ containing NBG perovskites are reported to have higher trap density of states $(t \mathrm{DOS})^{26}$, shorter carrier recombination lifetime $^{27}$, larger Urbach energy ${ }^{28}$, higher background carrier concentration due to oxidization of $\mathrm{Sn}^{2+}$ ions ${ }^{29}$, resulting in a high $V_{\mathrm{OC}}$ deficit, and lower absorption coefficient in near infrared region ${ }^{28}$ and low short-circuit current density $\left(J_{\mathrm{SC}}\right)$. The smaller absorption coefficient in near infrared region than in visible range in Sn containing NBG perovskites makes the problem even worse, because a much thicker perovskite film is needed to fully absorb the infrared part of sunlight.

To address these issues, many efforts have been devoted to improving the quality of Sn-containing NBG perovskites. Mhaisalkar and Mathews et al. effectively reduced the Sn vacancy density, which might cause the strong self-doping, by adding additive $\mathrm{SnF}_{2}{ }^{30}$. Jen and coworkers passivated the defeats of $\mathrm{Sn}$ containing NBG perovskites by ICBA and got an extremely low $V_{\mathrm{OC}}$ deficit of $0.33 \mathrm{~V}^{31}$. Most recent work by Yan et al. demonstrated enlarging grains and reducing electronic disorder of NBG perovskites using chlorine-containing additives in precursor solution $^{30}$. Nevertheless, the $J_{\mathrm{SC}}$ of NBG perovskite devices reported so far is still much lower than the theoretical limit. For example, a NBG perovskite with a bandgap of $1.22 \mathrm{eV}$, which is generally used in perovskite monolithic tandem cells, has a theoretical $J_{\mathrm{SC}}$ upper limit of $35.1 \mathrm{~mA} \mathrm{~cm}{ }^{-2}$ by assuming an external quantum efficiency (EQE) of $90 \%$ on average, while the highest reported $J_{\mathrm{SC}}$ is less than $30 \mathrm{~mA} \mathrm{~cm}{ }^{-2}$, and increased $J_{\mathrm{SC}}$ often causes reduction of $V_{\mathrm{OC}}$ or fill factor $(\mathrm{FF})^{23,32}$.

In this work, we find that the limiting factor for the far-from ideal $J_{\mathrm{SC}}$ in Sn-containing NBG PSCs is the much shorter electron diffusion length in comparison to the hole diffusion length. We report increasing the electron diffusion length to $2.72 \pm 0.15 \mu \mathrm{m}$ by adding a very small amount of $\mathrm{Cd}^{2+}$ ions into the precursor solution, allowing much thicker Sn-containing NBG active layer in PSCs to improve harvesting more infrared emission from sunlight. Employing $\mathrm{Cd}^{2+}$ ions enhances the PCE of both NBG single junction solar cells and monolithic all-perovskite tandem solar cells.

\section{Results}

Simulation of the NBG and monolithic perovskite tandem solar cells. To date, the reported narrowest bandgap of NBG perovskites is $\sim 1.22 \mathrm{eV}$ that gives matched $J_{\mathrm{SC}}$ with a wide bandgap (WBG) layer of around $1.80 \mathrm{eV}$ bandgap in a monolithic tandem solar cell ${ }^{21}$. Considering the main limitation for the PCE of NBG PSCs is from $J_{\mathrm{SC}}$, an optical simulation was performed to find out what is the optimal thickness of NBG perovskite layer in the tandem solar cells. Here, $\mathrm{FA}_{0.5} \mathrm{MA}_{0.45} \mathrm{Cs}_{0.05} \mathrm{~Pb}_{0.5} \mathrm{Sn}_{0.5} \mathrm{I}_{3}$ with a bandgap of $1.22 \mathrm{eV}$ and $\mathrm{FA}_{0.6} \mathrm{Cs}_{0.4} \mathrm{~Pb}\left(\mathrm{I}_{0.65} \mathrm{Br}_{0.35}\right)_{3}$ with a bandgap of $1.80 \mathrm{eV}$ are used for optical simulation in the perovskite-perovskite monolithic tandem solar cells. In the simulation, the $J_{\mathrm{SC}}$ of tandem cell is determined by the smaller one of the two sub-cells, where the EQEs in the whole absorption spectrum are set to be $90 \%$. As shown in Fig. 1a, the maximum $J_{\text {SC }}$ achievable for the tandem cell with these two chosen subcell bandgaps is $16.0 \mathrm{~mA} \mathrm{~cm}^{-2}$. In order to reach this maximum $J_{\mathrm{SC}}$, the NBG perovskite layer needs to be $1000 \mathrm{~nm}$ thick so that its photocurrent can match that from the $400 \mathrm{~nm}$ thick WBG perovskite layer. Figure $1 \mathrm{~b}$ shows the absorption coefficient of $\mathrm{Cs}_{0.05} \mathrm{MA}_{0.45} \mathrm{FA}_{0.5} \mathrm{~Pb}_{0.5} \mathrm{Sn}_{0.5} \mathrm{I}_{3}$, which also tells that a minimal thickness of $1000 \mathrm{~nm}$ is required for the NBG perovskite to absorb $90 \%$ of incident light in the near-infrared region.

Influence of $\mathrm{Cd}^{2+}$ on the performance of the NBG PSCs. Previous studies show that the optimized thickness for NBG cells was $620 \mathrm{~nm}^{32}$. Considering perovskites made in different labs might have a variation of film morphology and optoelectronic properties, we first systematically studied the thicknessdependent performance of NBG PSCs with the thicknesses ranging from 370 to $1140 \mathrm{~nm}$ as shown in Fig. 2a-e. Figure $2 \mathrm{f}$ shows the photocurrent curves of the NBG devices based on these films, and the performances are summarized in Supplementary Table 1. When the thickness of NBG perovskites is increased from 370 to $580 \mathrm{~nm}$, the $J_{\mathrm{SC}}$ increases from 25.4 to $27.3 \mathrm{~mA} \mathrm{~cm}^{-2}$, resulting an improved PCE from $16.8 \%$ to $18.1 \%$. However, as the perovskite thickness is further increased to $1140 \mathrm{~nm}$, the PCEs gradually reduce due to the decrease of $V_{\mathrm{OC}}$ from 0.85 to $0.75 \mathrm{~V}$, reduced $J_{\mathrm{SC}}$ from 27.33 to $24.54 \mathrm{~mA} \mathrm{~cm}^{-2}$, and reduced FF from 0.78 to 0.62 . This agrees with previously reported results ${ }^{31}$, showing those results are well reproduced.

Surprisingly, we discover that adding trace amount $(<0.1 \mathrm{~mol} \%)$ of $\mathrm{Cd}^{2+}$ ions into the precursor solution can significantly enhance the performance of NBG PSCs with $1000 \mathrm{~nm}$ thick perovskite layers. To find the optimal concentration of $\mathrm{Cd}^{2+}$ ions incorporation, we fixed the NBG film thickness to be $1000 \mathrm{~nm}$, and changed $\mathrm{Cd}^{2+}$ ions molar concentration from 0.01 to $0.07 \%$, by tuning the $\mathrm{CdI}_{2}$ ratio with $\mathrm{PbI}_{2}$ ratio in the precursor films. The $J-V$ and $\mathrm{EQE}$ curves of the related solar cell devices are shown in Fig. $2 \mathrm{~g}$ and Supplementary Fig. 1 and the related device performance is summarized in Supplementary Table 2. The optimized concentration of $\mathrm{Cd}^{2+}$ ions in the NBG perovskite precursors is found to be $0.03 \mathrm{~mol} \%$. We then did a same study of thickness-dependent performance of NBG PSCs with perovskite thicknesses ranging from 370 to $1140 \mathrm{~nm}$ and with a fixed $\mathrm{Cd}^{2+}$ ion concentration of $0.03 \mathrm{~mol} \%$ compared to $\mathrm{Pb}^{2+}$. The $J-V$ curves of these devices are shown in Fig. $2 \mathrm{~h}$ and device performance is summarized in Supplementary Table 3. When the thicknesses of the NBG perovskite are below $600 \mathrm{~nm}$, the PCEs of the NBG PSC are comparable to those devices without $\mathrm{Cd}^{2+}$ ions. Most notably, the $J_{\mathrm{SC}}$ of the Cd-containing devices continues to increase from 27.35 to $30.24 \mathrm{~mA} \mathrm{~cm}^{-2}$, and the device $V_{\mathrm{OC}}$ and FF remain unchanged, 

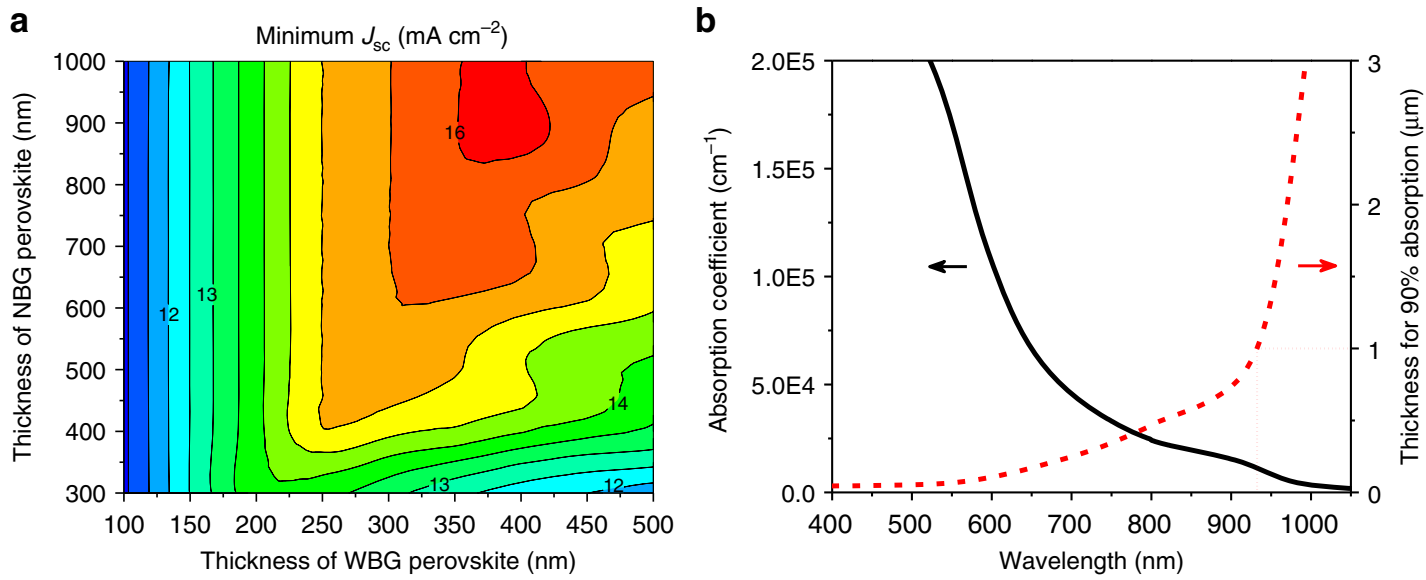

Fig. 1 Simulation of the NBG and monolithic perovskite tandem solar cells. a Simulated $J_{\mathrm{SC}}$ of perovskite-perovskite tandem solar cells with assumption of $90 \% \mathrm{EQE}$ in the whole absorption spectrum. In the simulation, the NBG $\mathrm{FA}_{0.5} \mathrm{MA}_{0.45} \mathrm{Cs}_{0.05} \mathrm{~Pb}_{0.5} \mathrm{Sn}_{0.5} \mathrm{I}_{3}$ and $\mathrm{WBG}_{\mathrm{FA}} \mathrm{A}_{0.6} \mathrm{Cs}_{0.4} \mathrm{~Pb}\left(\mathrm{I}_{0.65} \mathrm{Br}_{0.35}\right)_{3} \mathrm{Perovskites}$ have bandgaps of $1.22 \mathrm{eV}$ and $1.80 \mathrm{eV}$, respectively. $\mathbf{b}$ Absorption coefficient of $\mathrm{FA}_{0.5} \mathrm{MA}_{0.45} \mathrm{Cs}_{0.05} \mathrm{~Pb}_{0.5} \mathrm{Sn}_{0.5} \mathrm{I}_{3}$ with a bandgap of $1.22 \mathrm{eV}$, and corresponded thickness of the films that is needed to absorb $90 \%$ of different incident light. Source data are provided as a Source Data file
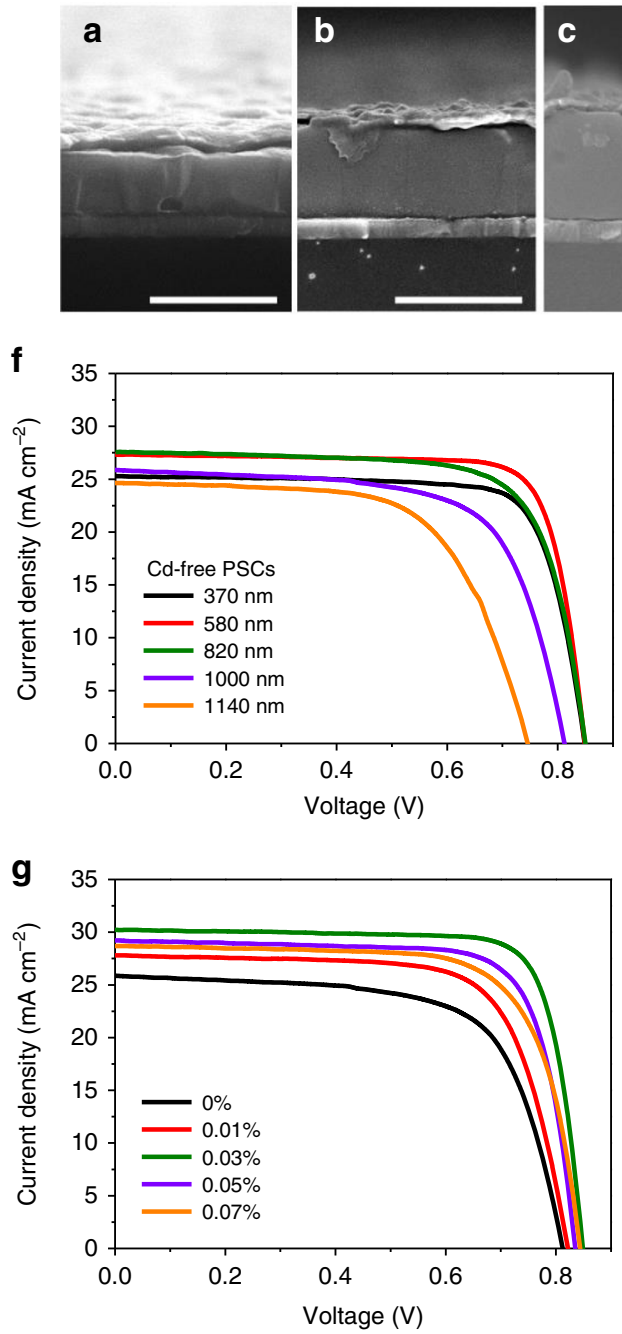


Fig. 2 Influence of $\mathrm{Cd}^{2+}$ on the performance of the NBG perovskite solar cells. a-e Cross-sectional SEM images of NBG PSCs without Cd2+ ions in different thicknesses of $370 \mathrm{~nm}(\mathbf{a}), 580 \mathrm{~nm}(\mathbf{b}), 820 \mathrm{~nm}(\mathbf{c}), 1000 \mathrm{~nm}(\mathbf{d})$ and $1140 \mathrm{~nm}(\mathbf{e})$, respectively. The scale bar is $1 \mu \mathrm{m}$ in all images. f $J-V$ characteristics of Cd-free NBG PSCs with different perovskite film thicknesses. $\mathbf{g} J-V$ characteristics of NBG PSCs with vary molar ratio of $C d^{2+}$ ions. $\mathbf{h}$ and $\mathbf{i} J-V$ characteristics (h) and EQE spectra (i) of NBG PSCs that was added with $0.03 \mathrm{~mol} \% \mathrm{Cd}^{2+}$ ions in different perovskite thicknesses. Source data are provided as a Source Data file 
when the thickness of NBG increases from 580 to $1000 \mathrm{~nm}$. This indicates that the charge collection length is increased in the NBG perovskite by the addition of $\mathrm{Cd}^{2+}$ ions. The device with $1000-\mathrm{nm}$ thick NBG perovskite layer exhibits a record PCE of $20.3 \%$ with negligible photocurrent hysteresis (Supplementary Fig. 2) among all reported highly efficient NBG PSCs with a high $V_{\mathrm{OC}}$ of $0.85 \mathrm{~V}, J_{\mathrm{SC}}$ of $30.24 \mathrm{~mA} \mathrm{~cm}^{-2}$ and FF of 0.79 (The comparison of device performance is shown in Supplementary Table 4). The efficiency is confirmed by the maximum power point output tracking, giving a stabilized PCE of $20.2 \%$ (Supplementary Fig. 3). The PCE of NBG PSCs drops slightly when the perovskite thickness is further increased to $1140 \mathrm{~nm}$, which is likely due to the worse morphology of the NBG perovskite films. Figure 2i shows the EQE spectra of the Cd-containing PSCs with perovskite layers of various thickness. The EQE in the near-infrared wavelength region $(800-1000 \mathrm{~nm})$ increases when the perovskite thickness is increased from $370 \mathrm{~nm}$ to $1000 \mathrm{~nm}$, in agreement with the improved $J_{\mathrm{SC}}$ from $J-V$ curves (Fig. 2h). The difference between integrated current density from $\mathrm{EQE}$ and $J_{\mathrm{SC}}$ from $J-V$ curve is within $3 \%$.

Electronic properties of NBG perovskites with and without $\mathbf{C d}^{2+}$ ions. To gain insight to the mechanism for improved performance in Cd-containing NBG PSCs, carrier diffusion length of electrons and holes in the NBG perovskites with and without $\mathrm{Cd}^{2+}$ ions were compared by measuring the carrier mobility and recombination lifetime. The mobilities of electrons and holes in the NBG perovskites with and without $\mathrm{Cd}^{2+}$ ions were measured via transient photocurrent decay (TPC), which characterize the charge transport process in real operational devices. The device structures and measurement setup are illustrated in Supplementary Fig. 4. The thicknesses of charge transport layers are so small that they do not impact the measured transit time ${ }^{33}$ (see part of transient photovoltage decay (TPV) and TPC measurement in the methods). It should be noted that the measurement of carrier mobility by TPC method needs to ensure the resistance-capacitance (RC) constant of the circuitry to be small enough so that it does not limit the charge transit time determination. Here we control the RC constant by decreasing device capacitance as summarized in Supplementary Tables 5 and 6 , which is realized via reducing the device active area with a laser scriber. Taking the electron mobility measurement as a sample, we gradually reduce the $\mathrm{RC}$ value of a $\mathrm{Cd}$-free NBG PSC by reducing the device area and measure the transit time. As shown by the TPC curves in Supplementary Fig. 5, when the RC value is reduced from 101.0 to $49.0 \mathrm{~ns}$, a reduction of transit time was clearly observed, despite the measurement being conducted using a same device. It indicates the transit time is limited by the RC constant in the large area devices. So, we further gradually reduced the RC value to $1.8 \mathrm{~ns}$, while we found the measured transit time reduced and stabilized at 22.0 $\mathrm{ns}$, which is determined to be the real transit time. Figure $3 \mathrm{a}$ shows that addition of $\mathrm{Cd}^{2+}$ ions reduces the electron transit time by around threefold from $22.0 \mathrm{~ns}$ to $7.2 \mathrm{~ns}$ in the devices with same thickness of NBG perovskites, which corresponds to an increase of electron mobility from $0.65 \mathrm{~cm}^{2} \mathrm{~V}^{-1} \mathrm{~s}^{-1}$ to $1.98 \mathrm{~cm}^{2} \mathrm{~V}^{-1} \mathrm{~s}^{-1}$. However, the TPC measurement for hole carriers are still limited by $R C$ constant, although it has been reduced to $3.1 \mathrm{~ns}$, as shown in Fig. $3 \mathrm{~b}$. We can still estimate that the hole mobilities are at least 3.86 and $3.25 \mathrm{~cm}^{2} \mathrm{~V}^{-1} \mathrm{~s}^{-1}$ in the NBG perovskites with and without $\mathrm{Cd}^{2+}$ ions, respectively.
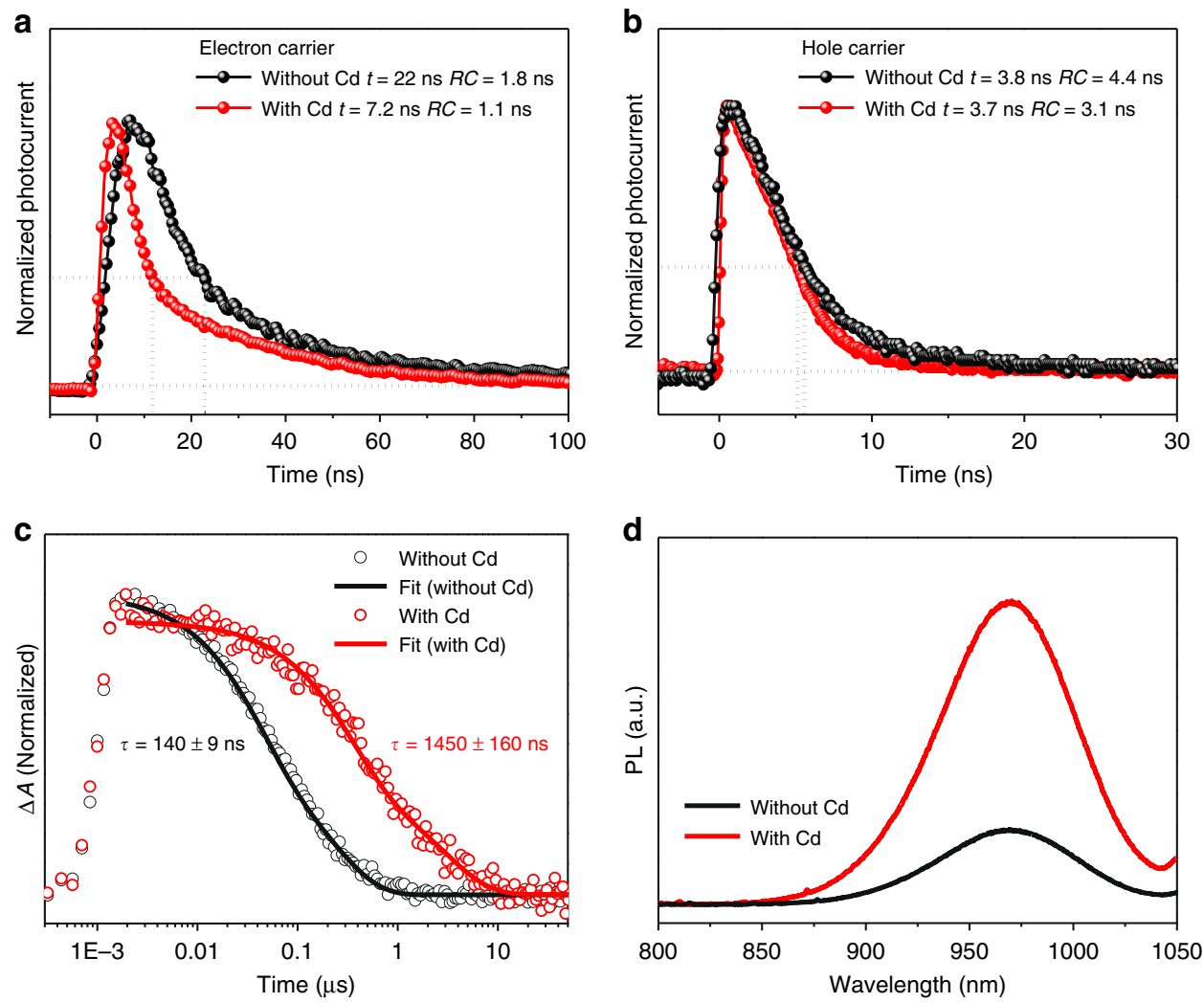

Fig. 3 Influence of $\mathrm{Cd}^{2+}$ ions on the carrier properties of NBG perovskites. $\mathbf{a}$ and $\mathbf{b}$ Normalized transient photocurrent of NBG PSCs with and without Cd ${ }^{2+}$ ions for electron (a) and hole (b) carriers. c TA kinetics near the exciton bleach ( $950 \mathrm{~nm}$ ) of NBG perovskites with and without C $\mathrm{d}^{2+}$ ions. $\tau$ is the average lifetime described in the method. $\mathbf{d}$ Steady-state PL of 1000-nm-thick NBG perovskite films with and without $\mathrm{Cd}^{2+}$ ions. All studies in Fig. 3 are based on 1000-nm-thick perovskite film. Source data are provided as a Source Data file 


\begin{tabular}{|c|c|c|c|c|}
\hline Species & $\begin{array}{l}\text { NBG PSCs } \\
(E g=1.22 \mathrm{eV})\end{array}$ & $\begin{array}{l}\begin{array}{l}\text { Mobility } \\
\left(\mathrm{cm}^{2} \mathbf{V}^{-1} \mathbf{s}^{-1}\right)\end{array} \\
\end{array}$ & $\begin{array}{l}\text { Recombination } \\
\text { lifetime (ns) }\end{array}$ & $\begin{array}{l}\text { Diffusion } \\
\text { length }(\mu \mathrm{m})\end{array}$ \\
\hline $\begin{array}{l}\text { Electron } \\
\text { Electron } \\
\text { Hole } \\
\text { Hole }\end{array}$ & $\begin{array}{l}\text { Without } \mathrm{Cd}^{2+} \\
\text { With } \mathrm{Cd}^{2+} \\
\text { Without } \mathrm{Cd}^{2+} \\
\text { With } \mathrm{Cd}^{2+}\end{array}$ & $\begin{array}{r}0.65 \\
1.98 \\
>3.25 \\
>3.86\end{array}$ & $\begin{array}{c}140 \pm 9 \\
1450 \pm 160 \\
140 \pm 9 \\
1450 \pm 160\end{array}$ & $\begin{array}{r}0.49 \pm 0.10 \\
2.72 \pm 0.15 \\
>1.08 \pm 0.10 \\
>3.80 \pm 0.20\end{array}$ \\
\hline
\end{tabular}

The carrier recombination lifetime in the perovskite films was measured by transient absorption (TA) spectroscopy. Figure 3c displays the normalized TA kinetics probed at the center of the ground-state bleach $(\sim 950 \mathrm{~nm})$ after $500-\mathrm{nm}$ excitation. The average carrier lifetime of the control NBG perovskite film is 140 $\pm 9 \mathrm{~ns}$, while it is significantly increased to $1450 \pm 160 \mathrm{~ns}$ after adding $\mathrm{Cd}^{2+}$ ions into the perovskite films, comparable to the best recently reported lifetime ${ }^{34}$. This agrees with the enhanced photoluminescence $(\mathrm{PL})$ intensity in the Cd-containing perovskite films, as shown in Fig. 3d. The carrier recombination process in the PSCs was also measured by the TPV method, though the measured lifetime is also affected by charge combination at interfaces in the devices. As shown by the TPV curves in Supplementary Fig. 6, the Cd-containing PSCs also have doubled charge recombination lifetime compared to the control device, indicating the charge recombination inside the perovskite films dominates. All carrier mobility, recombination lifetime and diffusion length are summarized in Table 1. The calculated electron diffusion length of Cd-free PSCs is only $0.49 \pm 0.10 \mu \mathrm{m}$, which explains the decreased device PCE when the perovskite thickness is increased to beyond $600 \mathrm{~nm}$. The electron diffusion length is significantly improved to $2.72 \pm 0.15 \mu \mathrm{m}$ after adding $\mathrm{Cd}^{2+}$ ions into the perovskite layer, more than fivefold of the value from the Cd-free device. The long electron diffusion length enables efficient electron extraction in 1000 -nm-thick perovskite film, affording the high performance in thick Cd-containing PSCs. On the other hand, the hole diffusion length in NBG perovskites with and without $\mathrm{Cd}^{2+}$ ions are calculated to be more than $3.80 \pm$ 0.20 and $1.08 \pm 0.10 \mu \mathrm{m}$, respectively, indicating the hole extraction is not a limiting factor in the NBG PSCs with 1000-nm-thick perovskite layer. Although there has been speculation in the past on the short carrier diffusion length in Sn-perovskites, there is no study to identify what the limiting factor is. Here we conclude the short electron diffusion length is the key limiting factor hindering the performance enhancement of NBG PSCs.

To understand the origin of improved electron diffusion length, we first compared the morphology of perovskite films with and without $\mathrm{Cd}^{2+}$ ions with a concentration of $0.03 \mathrm{~mol} \%$ by scanning electron microscopy (SEM). As shown in the crosssectional and top view SEM images in Supplementary Figs. 7 and $8 \mathrm{f}-\mathrm{j}$, the grain sizes of $\mathrm{Cd}$-containing films are similar with those of Cd-free perovskite films (Fig. 2a-e and Supplementary Fig. 8a-e), which is not surprising because of the very small amount of $\mathrm{Cd}^{2+}$ ions added. It indicates the enhanced electron diffusion length is not originated from a change in morphology. In addition, no obvious change of lattice constant, optical properties and photostability of the perovskite films have been observed, again consistent with the small amount of $\mathrm{Cd}^{2+}$ ions added (Supplementary Figs. 9-11). Despite the small amount, their existence of $\mathrm{Cd}^{2+}$ in the NBG perovskite films is confirmed by X-ray photoelectron spectroscopy (XPS) study. As shown in Supplementary Fig. 12, a characteristic peak of $\mathrm{Cd}^{2+} 3 \mathrm{~d}$ clearly shows up in the perovskite film with $\mathrm{Cd}^{2+}$, in contract to the control Cd-free NBG perovskites.
The two major factors that determine minority carrier recombination process in a semiconductor are background majority carrier concentration and non-radiative trap density. Therefore, the background majority carrier concentration of the NBG perovskite was measured with a capacitance-voltage method. As shown in Fig. 4a, the measured background carrier concentration of the NBG perovskite decreases from $1.0 \times 10^{16} \mathrm{~cm}^{-3}$ to $4.2 \times 10^{15} \mathrm{~cm}^{-3}$ after adding $\mathrm{Cd}^{2+}$ ions, which indicates that $\mathrm{Cd}^{2+}$ ions de-dope the NBG perovskite. Previous studies revealed Sn vacancies are the most abundant intrinsic defects in Sn-based perovskites $^{26}$, which induces self-doping of Sn perovskite. $\mathrm{Cd}^{2+}$ ions with a relative smaller ionic radius are reported to incorporate into the lattice of $\mathrm{Pb}$-based perovskites to reduce internal strain 35 Therefore, we propose that the $\mathrm{Cd}^{2+}$ ions can fill the $\mathrm{Sn}$ vacancies to de-dope $\mathrm{Sn}$ perovskite, which enhances minority carrier recombination lifetime, carrier mobility and diffusion length.

Temperature-dependent thermal admittance spectroscopy was conducted to determine the $t \mathrm{DOS}$ and depth of traps with a regular solar cell structure. A clear trap state with average activation energy of $90 \mathrm{meV}$ can be derived from the temperature-dependent capacitance-frequency measurement in the Cd-free perovskite devices as shown in Fig. $4 \mathrm{~b}$ and Supplementary Fig. 13. The density of this trap state at $295 \mathrm{~K}$ reduces by more than one order of magnitude after adding $\mathrm{Cd}^{2+}$ ions as shown in Fig. 4c, indicating an excellent passivation effect of $\mathrm{Cd}^{2+}$ ions. The reduction of trap density by $\mathrm{Cd}^{2+}$ ions is further confirmed by time-resolved microwave conductance (TRMC) study with a varied incident light intensity. Using a sample structure of quartz/charge-accepting layers/perovskite, the effect of $\mathrm{Cd}^{2+}$ ions on change of electron and hole trap density can be determined. Here poly(3,4-ethylenedioxythiophene):poly (styrene-sulfonate) (PEDOT:PSS) and [6,6]-phenyl- $\mathrm{C}_{61}$-butyric acid methyl ester (PCBM) are inserted to extract photogenerated holes and electrons, respectively. As shown in Fig. 4d, the electron recombination lifetimes of Cd-free film gradually increase with the increasing incident light intensity, which suggests the existence of electron traps. While the electron recombination lifetime of Cd-containing film almost maintains the same at varied exciting light intensity, as shown in Fig. 4e. For the films with PCBM, the hole recombination kinetics is found to be largely unchanged, as shown in Supplementary Fig. 14. This proves that adding $\mathrm{Cd}^{2+}$ ions into the NBG perovskite mainly reduces the density of electron traps. This result agrees well with the $t \mathrm{DOS}$ measurement and reveals the mechanism for the improved electron carrier mobility. Filling of charge traps will generally affect diode ideality factor because of charged charge recombination mechanism. Therefore, we conducted light-intensitydependent $J-\mathrm{V}$ measurements to derive the ideality factor of the PSCs, since the charge recombination behavior can be indicated by the device ideality factor ${ }^{36}$. As seen in Fig. $4 \mathrm{f}$, the drop of ideality factor by adding $\mathrm{Cd}^{2+}$ ions is in consistent with the improved optoelectronic properties. We conclude that adding $\mathrm{Cd}^{2+}$ ions not only de-dopes the NBG perovskite, but also reduces the electron trap density, which enhances minority carrier mobility, recombination lifetime and diffusion length.

Photovoltaic performance of tandem solar cells. Finally, this Cd-containing NBG perovskite was used in perovskite-perovskite monolithic tandem solar cells with a structure of ITO/PTAA/ $\mathrm{FA}_{0.6} \mathrm{Cs}_{0.4} \mathrm{~Pb}\left(\mathrm{I}_{0.65} \mathrm{Br}_{0.35}\right)_{3} \quad(1.80 \mathrm{eV}) / \mathrm{C}_{60} / \mathrm{SnO}_{2} / \mathrm{ITO} / \mathrm{PEDOT}: \mathrm{PSS} /$ PTAA/Cd-FA ${ }_{0.5} \mathrm{MA}_{0.45} \mathrm{Cs}_{0.05} \mathrm{~Pb}_{0.5} \mathrm{Sn}_{0.5} \mathrm{I}_{3} / \mathrm{C}_{60} / \mathrm{BCP} / \mathrm{Cu}$ shown in Fig. 5a, b. The 1000-nm-thick NBG perovskite and $400 \mathrm{~nm}$ WBG perovskite were applied in the tandem structure to maximize the $J_{\text {SC }}$ according to our optical simulation results shown in Fig. 1a. The best single junction WBG PSC has a PCE of $16.3 \%$ with a 

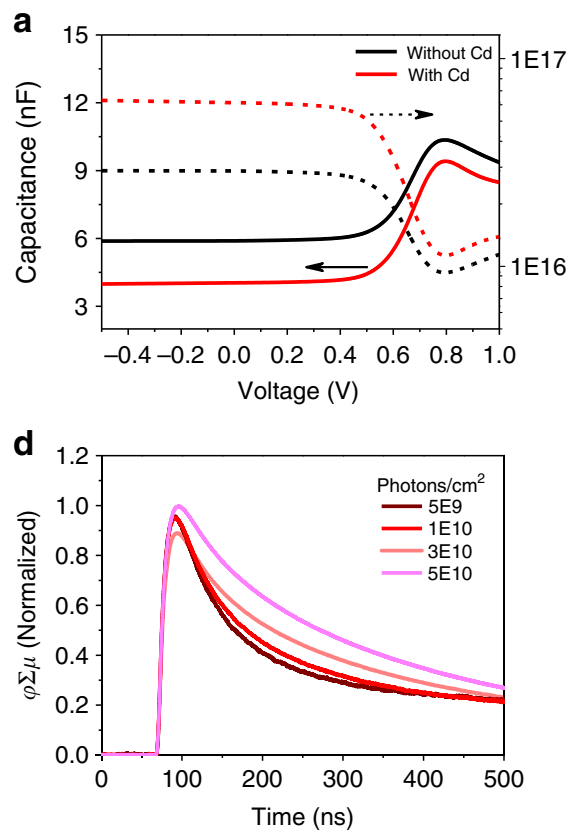
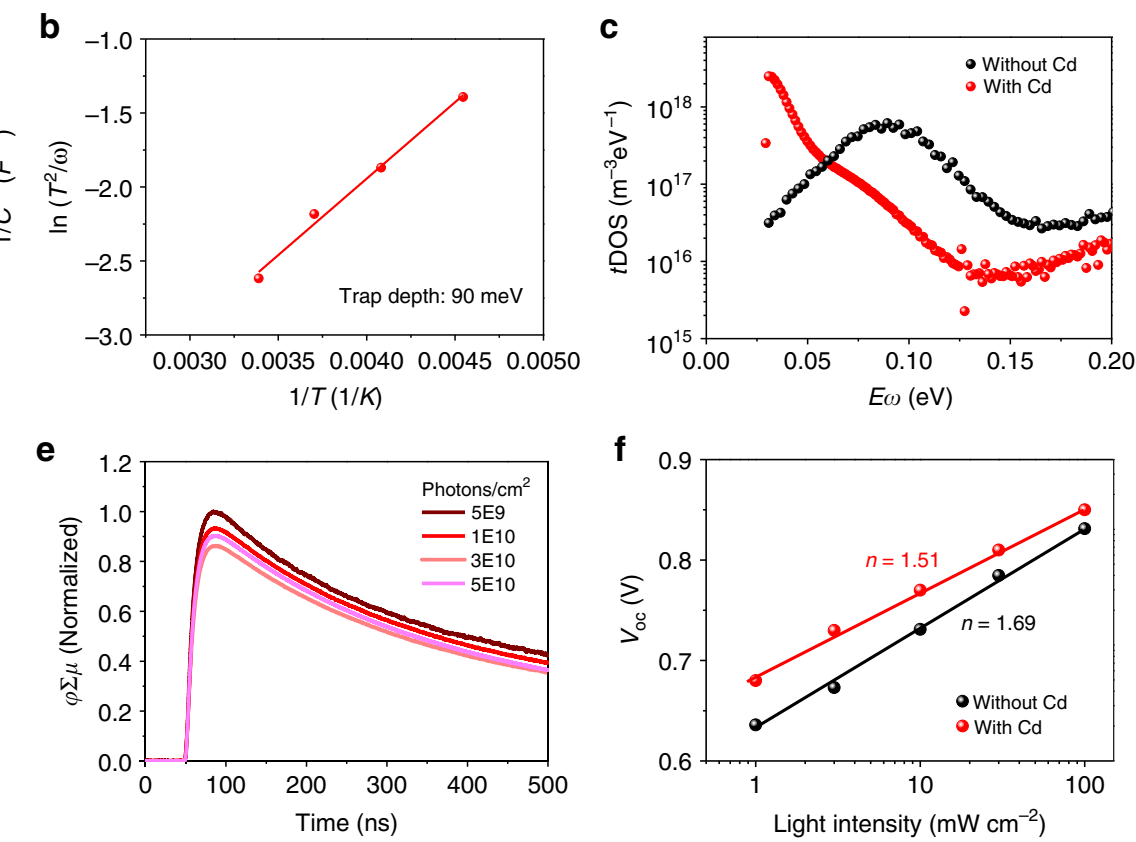

Fig. 4 Influence of $\mathrm{Cd}^{2+}$ ions on the carrier concentration and tDOSs. a Capacitance-voltage curves of NBG PSCs with and without Cd ${ }^{2+}$ ions at $295 \mathrm{~K}$. $\mathbf{b}$ In $\left(T^{2} / \boldsymbol{\omega}\right)$ vs $1 / T$ curve for determining the trap depth and attempt-to-escape angular frequency. c $t$ DOS studies of NBG PSCs with and without Cd ${ }^{2+}$ ions at $295 \mathrm{~K}$. d and e TRMC measurement for electron carrier property with a structure of quartz/PEDOT:PSS/NBG perovskite films without (d) and with (e) Cd2+ ions. The intensities are normalized to the highest peak intensity. $\mathbf{f} \mathrm{V}_{\mathrm{OC}}$ evolution with light intensity of NBG PSCs with and without $\mathrm{Cd}{ }^{2+}$ ions. All studies in Fig. 4 are based on 1000-nm-thick perovskite film. Source data are provided as a Source Data file

a

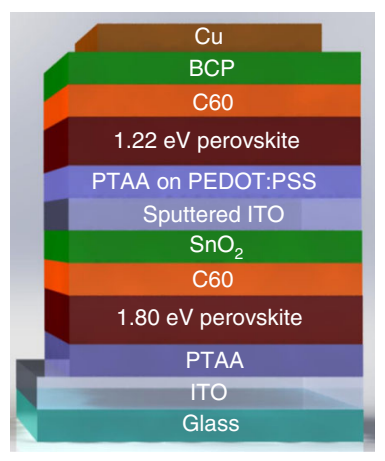

d

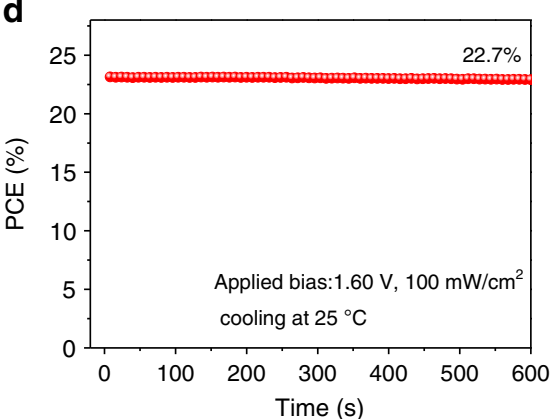

b

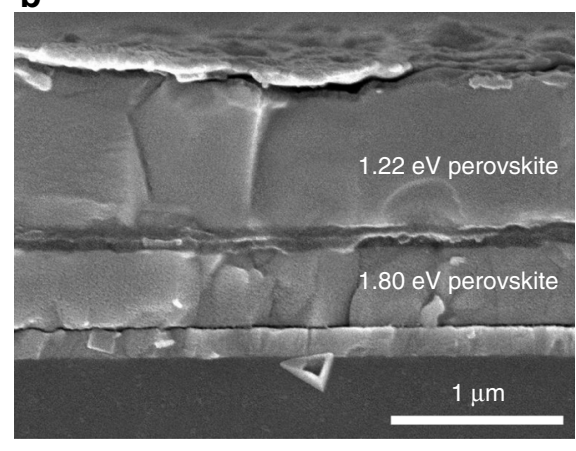

e

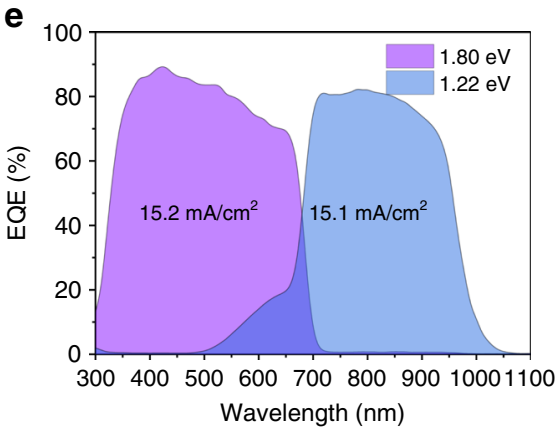

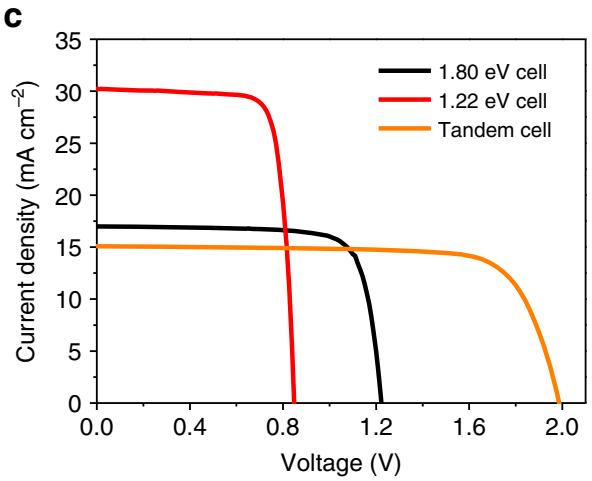

f

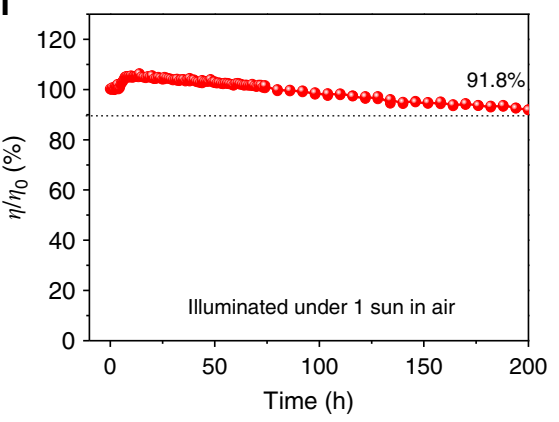

Fig. 5 Perovskite-perovskite monolithic tandem cells with $\mathrm{Cd}^{2+}$ ions in NBG perovskites. a, b Illustration and cross-sectional SEM image of a perovskite-perovskite tandem solar cell. $\mathbf{c} J-V$ characteristics of tandem solar cell and individual WBG and NBG single junction PSCs. d Steady-state output of tandem solar cells at the maximum power point (applied bias of $1.60 \mathrm{~V}$ ) under AM1.5 illumination at $25^{\circ} \mathrm{C}$. e Individual EQE spectra of WBG and NBG sub-cells in the tandem solar cells. $\mathbf{f}$ Long-term photo stability test of the tandem solar cells under continuous AM1.5 illumination. $\eta$ and $\eta_{0}$ represent the evaluated and initial PCEs, respectively. Source data are provided as a Source Data file 
Table $2 \mathrm{~J}-\mathrm{V}$ characteristics of individual WBG and NBG single-junction PSCs and their tandem solar cells measured under AM1.5 illumination

\begin{tabular}{lllll} 
Cell type & $\mathbf{V}_{\mathbf{O C}}(\mathbf{V})$ & $\mathbf{J}_{\mathbf{S C}}\left(\mathbf{m A ~ \mathbf { ~ c m }}{ }^{-\mathbf{2}}\right)$ & $\mathbf{F F}$ & PCE (\%) \\
\hline Single junction, bandgap of $1.80 \mathrm{eV}$ & $1.21 \pm 0.03(1.22)$ & $16.5 \pm 0.6(17.0)$ & $0.77 \pm 0.2(0.78)$ & $15.5 \pm 0.5(16.3)$ \\
Single junction, bandgap of $1.22 \mathrm{eV}$ & $0.83 \pm 0.03(0.85)$ & $29.7 \pm 0.6(30.2)$ & $0.78 \pm 0.02(0.79)$ & $19.4 \pm 0.6(20.3)$ \\
Tandem solar cells & $1.95 \pm 0.02(1.99)$ & $15.0 \pm 0.3(15.1)$ & $0.76 \pm 0.2(0.77)$ & $22.2 \pm 0.4(23.0)$ \\
\hline
\end{tabular}

Average values with standard deviation. The data for single junction and tandem devices was obtained from 20 and 50 devices, respectively. Parameters of the best cell are reported in brackets

$V_{\mathrm{OC}}$ of $1.22 \mathrm{~V}, J_{\mathrm{SC}}$ of $17.0 \mathrm{~mA} \mathrm{~cm}^{-2}$ and $\mathrm{FF}$ of 0.78 (Fig. $5 \mathrm{c}$ and Table 2). When combined with the optimized Cd-containing NBG PSC, the best tandem solar cell achieves a highest PCE of $23.0 \%$ under reverse scan with a $V_{\mathrm{OC}}$ of $1.99 \mathrm{~V}$, a $J_{\mathrm{SC}}$ of $15.1 \mathrm{~mA} \mathrm{~cm}^{-2}$ and FF of 0.77 as shown in Fig. $5 \mathrm{c}$ and S15. The PCE of the tandem cells was further confirmed by tracking steady-state output at maximum power point. A stabilized PCE of $22.7 \%$ is observed after continuous illumination for $600 \mathrm{~s}$ (Fig. 5d). To understand the current matching between WBG and NBG sub-cells in the tandem solar cells, EQE spectra of sub-cells were measured and are shown in Fig. 5e. The integrated $J_{S C}$ of WBG and NBG sub-cells are 15.2 and $15.1 \mathrm{~mA} \mathrm{~cm}^{-2}$, respectively, which agree with the $J_{\mathrm{SC}}$ from $J-V$ measurements. The optical simulation further confirms the front WBG subcell does not affect the light absorption of the back NBG subcell in a tandem structure as shown in Supplementary Figs. 16 and 17. Finally, the photostability of encapsulated tandem cells is measured in ambient condition with humidity of $30-50 \%$. As shown in Fig. 5f, a tandem cell maintains $91.8 \%$ of their initial PCE after being illuminated under 1 sun for $200 \mathrm{~h}$. PCE statistics for tandem solar cells is shown in Supplementary Fig. 18 and Supplementary Table 7 .

\section{Discussion}

In conclusion, we find that the short electron diffusion length is the main limitation factor in realizing a highly efficient $\mathrm{Sn}$-based NBG PSCs. The electron diffusion length is effectively enhanced by three times to $2.72 \pm 0.15 \mu \mathrm{m}$ by adding $0.03 \mathrm{~mol} \%$ of $\mathrm{Cd}^{2+}$ ions in the perovskite, which enables much thicker Sn-perovskite layers for harvesting more infrared light. The NBG PSCs with optimal perovskite thickness of $1000 \mathrm{~nm}$ demonstrate exceptional stabilized efficiencies of $20.2 \%$. By coupling with a WBG perovskite, a high PCE of $22.7 \%$ is achieved in a monolithic perovskite-perovskite tandem cell. This work provides a promising method to enhance the optoelectronic properties of NBG perovskites, which unlock the potential of high-efficiency, lowcost and solution-processable perovskite-perovskite tandem solar cells.

\section{Methods \\ Materials. Formamidine iodide, methylammonium iodide were purchased from Greatcell Solar company. $\mathrm{PbI}_{2}$ (99.999\%), $\mathrm{PbBr}_{2}$ (99.999\%), $\mathrm{SnI}_{2}$ (99.999\%), $\mathrm{CdI}_{2}$ (99.999\%), $\mathrm{SnF}_{2}$ (99\%), CsI (99.999\%), N,N-dimethylformamide (99.8\%, anhy- drous), dimethyl sulfoxide (99.8\%, anhydrous), 1,2-dichlorobenzene (99\%), toluene (anhydrous, 99.8\%), poly(bis(4-phenyl)(2,4,6-trimethylphenyl)amine)(PTAA) and bathocuproine (BCP) were purchased from Sigma-Aldrich. Acetone and iso- propanol alcohol were purchased from VWR company. PCBM and $\mathrm{C}_{60}$ were purchased from NANO-C company. PEDOT:PSS (Clevios ${ }^{\mathrm{Tm}}$ P VP AI 4083) was purchased from Heraues company.}

Preparation of perovskite precursor solutions. A total of $1.35 \mathrm{M}$ WBG perovskite $\mathrm{FA}_{0.6} \mathrm{Cs}_{0.4} \mathrm{~Pb}\left(\mathrm{I}_{0.65} \mathrm{Br}_{0.35}\right)_{3}$ precursor solution was prepared by dissolving $0.139 \mathrm{~g}$ of $\mathrm{CH}\left(\mathrm{NH}_{2}\right)_{2} \mathrm{I}, 0.140 \mathrm{~g}$ of CsI, $0.249 \mathrm{~g}$ of $\mathrm{PbI}_{2}$ and $0.297 \mathrm{~g}$ of $\mathrm{PbBr}_{2}$ in a mixed solvent of DMSO and DMF with a volume ratio of 3:7. NBG perovskite $\mathrm{FA}_{0.5} \mathrm{MA}_{0.45} \mathrm{Cs}_{0.05} \mathrm{~Pb}_{0.5} \mathrm{Sn}_{0.5} \mathrm{I}_{3}$ precursor solution with a concentration of 1.2-2.1 M was prepared by dissolving $0.45 \mathrm{~mol}$ of MAI, $0.5 \mathrm{~mol}$ of FAI, $0.05 \mathrm{~mol}$ of CsI, 0.55 mol of $\mathrm{PbI}_{2}, 0.5 \mathrm{~mol}$ of $\mathrm{SnI}_{2}$ and $0.05 \mathrm{~mol}$ of $\mathrm{SnF}_{2}$ in a mixed solvent of DMSO and DMF with a volume ratio of 3:7. A total of $0.2 \mathrm{M} \mathrm{CdI}_{2}$ in DMF is prepared as additive for perovskite precursors. All the perovskite solutions were filtered with polytetrafluoroethylene (PTFE) filters $(0.22 \mu \mathrm{m})$ before use. The NBG perovskite films with thicknesses of $370,580,820,1000$ and $1140 \mathrm{~nm}$ are prepared by spincoating $1.3 \mathrm{M}$ precursor solution under $5 \mathrm{~K} \mathrm{r.p.m.,} 1.6 \mathrm{M}$ precursor solution under $5 \mathrm{~K}$ r.p.m., $1.6 \mathrm{M}$ precursor solution under $3.5 \mathrm{~K} \mathrm{r.p.m.,} 1.8 \mathrm{M}$ precursor solution under $3.5 \mathrm{~K} \mathrm{r.p.m}$. and $2.0 \mathrm{M}$ precursor solution under $3.5 \mathrm{~K} \mathrm{r.p.m.,} \mathrm{respectively.}$

Device fabrication. Patterned ITO glass substrates were cleaned by sequential ultrasonication in acetone and isopropyl alcohol for $30 \mathrm{~min}$. Then, the ITO substrates were further cleaned via UV ozone treatment for $20 \mathrm{~min}$. For the fabrication of NBG PSCs, PEDOT:PSS solution was spin-coated onto the ITO substrates at 5000 r.p.m. for $30 \mathrm{~s}$ and anneal at $150^{\circ} \mathrm{C}$ for $10 \mathrm{~min}$ in ambient condition. After the substrates were transfer into the glovebox, a diluted $0.5 \mathrm{mg} \mathrm{mL}^{-1}$ PTAA solution was spin-coated at a speed of 8000 r.p.m. for $30 \mathrm{~s}$ and annealed at $100{ }^{\circ} \mathrm{C}$ for $10 \mathrm{~min}$. Then $50 \mu \mathrm{L}$ of NBG perovskite precursor solution was spin-coated for $30 \mathrm{~s}$ $0.3 \mathrm{~mL}$ of PCBM solution in toluene $\left(1 \mathrm{mg} \mathrm{mL}^{-1}\right)$ was quickly dropped onto the spinning substrate after $10 \mathrm{~s}$ elapsed, followed by annealing at $100{ }^{\circ} \mathrm{C}$ for $10 \mathrm{~min}$. The thicknesses were controlled by tuning the concentration of precursor solution and spin coating speed. Finally, $20 \mathrm{~nm} \mathrm{C} 60,6 \mathrm{~nm} \mathrm{BCP}$ and $80 \mathrm{~nm} \mathrm{Cu}$ were sequentially thermal evaporated onto the perovskite films to complete the fabrication of single junction NBG PSCs. For the fabrication of tandem solar cells, $2 \mathrm{mg} \mathrm{mL}^{-1}$ PTAA solution was spin-coated onto the ITO substrates at the speed of 5000 r.p.m. for $30 \mathrm{~s}$, followed by annealing at $100^{\circ} \mathrm{C}$ for $10 \mathrm{~min}$. After the PTAAcoated substrates were pre-wetted by spinning $50 \mu \mathrm{L}$ of DMF at 5000 r.p.m. for $10 \mathrm{~s}, 50 \mu \mathrm{L}$ of WBG perovskite precursor solution was spin-coated onto PTAA at 5000 r.p.m. for $20 \mathrm{~s}$ and 1000 r.p.m. for 20 s. A nitrogen flow is blown onto the substrate for fast drying in the 20th second. Next, the samples were annealed at $65^{\circ} \mathrm{C}$ for $10 \mathrm{~min}$ and $100{ }^{\circ} \mathrm{C}$ for $10 \mathrm{~min}$. After thermal evaporating $30 \mathrm{~nm} \mathrm{C}_{60}$ onto the perovskite films, $13 \mathrm{~nm} \mathrm{SnO}_{2}$ film was deposited by atomic layer deposition method under vacuum of $0.2 \mathrm{mTorr}$ at $100^{\circ} \mathrm{C}$ with $\left[\left(\mathrm{CH}_{3}\right)_{2} \mathrm{~N}\right]_{4} \mathrm{Sn}$ and $\mathrm{H}_{2} \mathrm{O}$ as $\mathrm{Sn}$ and $\mathrm{O}$ sources. Afterward, $10 \mathrm{~nm}$ ITO was sputtered onto $\mathrm{SnO}_{2}$ as recombination layer by a Lesker Sputter system (PRO Line ${ }^{\mathrm{TN}}$ PVD $75^{\mathrm{TN}}$ ) with low power of $100 \mathrm{~W}$ (RF mode) under a 3 mTorr mixed gas of $\mathrm{Ar}$ and $\mathrm{O}_{2}$ at room temperature. Soon after, PEDOT:PSS solution was spin-coated onto the ITO substrates at 5000 r.p.m. for $30 \mathrm{~s}$ and anneal at $100{ }^{\circ} \mathrm{C}$ for $20 \mathrm{~min}$ in ambient condition. Then repeating the fabrication procedure of NBG PSCs as described above to complete the tandem solar cells. Different solar cells in one device substrate were separated by laser scribing (Resonetics Rapid X250 laser ablation system) for avoiding the connection in the middle-sputtered ITO layer. The device areas of all solar cells are $8 \mathrm{~mm}^{2}$.

Device and material characterizations. J-V measurement: Simulated AM $1.5 \mathrm{G}$ irradiation was produced by a Newport Oriel Sol3A solar simulator (Oriel 94943A $450 \mathrm{~W}$ ) with an AM1.5 filter. The light intensity was calibrated by a reference Si solar cells and meter $(\mathrm{P} / \mathrm{N} 5110 \mathrm{~V}$, Newport). $J-V$ measurements of solar cells are performed by a Keithley 2400 Source meter under AM $1.5 \mathrm{G}$ illumination at reverse scan mode with a scan rate of $0.05 \mathrm{~V} \mathrm{~s}^{-1}$. For the long-term stability measurement, the tandem devices were encapsulated with Gorilla clear epoxy and slide glass and connected to a resistor so that it can operate at its maximum power point under illumination. Then it was characterized under constant AM 1.5G illumination in ambient condition with a relative humidity between $30 \%$ and $50 \%$ at room temperature that was maintained by a cooling stage. All single junction and tandem devices were measured by applying a shadow mask with an aperture area of $6.84 \mathrm{~mm}^{2}$.

EQE measurements: EQE measurements were conducted with a Newport QE measurement kit by focusing a monochromatic beam of a Bruker Vertex $80 \mathrm{v}$ Fourier Transform Interferometer with tungsten lamp source onto the devices. Then the photocurrent was obtained through Stanford Research SR570 current preamplifier. EQE of devices were calibrated by a Newport reference silicon solar cell with a known EQE. The EQE of WBG and NBG sub-cells in tandem cells were measured by respectively exposing the tandem cell under a $470-\mathrm{nm}$ and $940-\mathrm{nm}$ LED lamp for saturating the other junction during measurement.

TPV and TPC measurements: For the TPV measurements, the solar cells were connected to a digital oscilloscope (DOS-X 3104A) and illuminated by a solar simulator with 1 sun intensity to form an open-circuit condition (the internal impedance of the oscilloscope was set to $1 \mathrm{M} \Omega$ ). An attenuated $337 \mathrm{~nm}$ laser pulse (SRS NL 100 Nitrogen Laser, frequency of $10 \mathrm{~Hz}$ and pulse width of $<3.5 \mathrm{~ns}$.) was applied as a small perturbation to the 1 sun background illumination on the device. 
The laser-pulse induces a photovoltage variation $(\Delta V)$ to the $V_{\mathrm{OC}}$ that produced by 1 sun background illumination. For the TPC measurement, the device was also connected to the oscilloscope and the internal impedance was set to $50 \Omega$ to form a short-circuit condition. A photocurrent variation $(\Delta I)$ is produced by a same laser pulse that is used in TPV measurement. No background illumination is used in TPC measurement. The carrier mobility $\mu$ were calculated from the relationship of $\mu=d^{2} / t V_{\mathrm{bi}}$, where $d, V_{\mathrm{bi}}$ and $t$ are transit distance, built-in potential and transit time, respectively ${ }^{6}$. We calculated charge transit time to verify which layer is the limiting $J_{\mathrm{SC}}$ transit time. The thickness and mobility of $\mathrm{C}_{60}$ is just $20 \mathrm{~nm}$, and the mobility is about $0.1-$ to $1 \mathrm{~cm}^{2} \mathrm{~V}^{-1} \mathrm{~s}^{-1}$. The diffuse time of carrier transport through $\mathrm{C}_{60}$ layer is calculated to be $0.15-1.5 \mathrm{~ns}$. The real transit time is even shorter, because of the additional built-in electric field. This transit time is far smaller than what we measured in the TPC measurement. Therefore, the electron transit time is not limited by the $\mathrm{C}_{60}$ layer.

tDOS measurement: Temperature-dependent thermal admittance spectroscopy is used to measure the energetic profile of trap density, and the $t \mathrm{DOS}$ of the devices $\left(N_{\mathrm{T}}\right)$ are calculated by the equation $N_{T}\left(E_{\boldsymbol{\omega}}\right)=-\frac{1}{q k_{\mathrm{B}}} \frac{\omega}{d \omega} \frac{V_{\boldsymbol{\omega}}}{W}$, where $W$ and $V_{\mathrm{bi}}$ are the depletion width and build-in potential, respectively, that were derived from Mott-Schottky analysis; $q, k_{\mathrm{B}}, T$, $\boldsymbol{\omega}$ and $C$ are elementary charge, Boltzmann's constant, temperature, angular frequency and capacitance, respectively ${ }^{37}$. An energetic demarcation is defined by the applied angular frequency $\omega$ :

$E_{\omega}=k_{\mathrm{B}} T \ln \frac{\omega_{0}}{\omega}$, where $\omega_{0}$ is the attempt-to-escape angular frequency. The activation energy of trap states and attempt-to-escape frequency are calculated to be $90 \mathrm{meV}$ and $3.76 \mathrm{MHz}$ according to the relationship $\ln \left(\frac{T^{2}}{\omega}\right)=\frac{E_{\mathrm{T}}}{k T}-\ln \left(2 \pi v_{0}\right)$, where $T, \boldsymbol{\omega}$, $E_{\mathrm{T}}, k, v_{0}$ are temperature, angular frequency, activation energy of trap states, Boltzmann constant and attempt-to-escape frequency, respectively. For the depletion width of devices in vary temperatures, according to the capacitance-voltage measurement at $295 \mathrm{~K}$ as shown in Fig. 3i, the capacitance does not change when there is a reverse bias, indicating the device is fully depleted, i.e. the depletion width is equal to the thickness of perovskite film, which is $\sim 1 \mu \mathrm{m}$. The depletion width increases when the temperature decreases according to their relationship $W_{D}=\sqrt{\frac{2 \varepsilon}{q N}\left(V_{\mathrm{bi}}-V-\frac{2 k T}{q}\right)}$, mainly due to reduced dark carrier density. Therefore, the depletion widths measured at all temperatures from 220 to $295 \mathrm{~K}$ in this work are about $1 \mu \mathrm{m}$. The trap states below the energy demarcation are able to capture or emit carriers with the given $\omega$ and contribute to the capacitance.

TA measurement: Microsecond TA spectra were collected using a Helios spectrometer (Ultrafast systems). A Coherent Libra regeneratively amplified Ti: sapphire laser with $\sim 4 \mathrm{~W}, 1 \mathrm{kHz}$ and $\sim 150 \mathrm{fs}$ pulse-width output at $800 \mathrm{~nm}$ was used for pump-beam generation. The $800-\mathrm{nm}$ beam was directed into a TOPAS optical parametric amplifier to generate a pump pulse at $500 \mathrm{~nm}$. The probe beam is derived from an EOS system and was electronically delayed with respect to pump laser pulse. The probe beam produced was a broadband near infrared spectrum from 850 to $1600 \mathrm{~nm}$. The probe was then passed through a continuously variable neutral-density filter and a fraction was separated off to be used as a reference that accounts for probe-beam intensity fluctuations. The pump and probe beams were then overlapped at the sample. Near infrared photodiode arrays (Ultrafast Systems) were used to detect the probe and reference beams for data acquisition. To extract the lifetime of charge carriers, the transient kinetics is modeled with a biexponential decay function and the average lifetime $(\tau)$ is reported here as $\tau=\frac{A_{1} \tau_{1}+A_{2} \tau_{2}}{A_{1}+A_{2}}$.

TRMC: For the TRMC measurements, the perovskite films were deposited onto quartz substrates $\left(2.75 \mathrm{~cm}^{2}\right.$ area). The samples are pumped with a 5 -ns pulse width beam $(640 \mathrm{~nm})$ from an OPO pumped by the third harmonic of an Nd:YAG laser, and probed by microwaves at around $9 \mathrm{GHz}$. The microwave field is absorbed by photogenerated mobile carriers in the NCs, and its relative change in power $\Delta P$ can be measured. The change in microwave power relates to the photoconductivity $\Delta G$ through $\Delta P / P=-K \Delta G$, where $K$ is an empirically determined calibration factor for the microwave cavity used in this experiment. The photoconductivity is proportional to the number of charges and their mobility. It can be expressed as $\Delta G=e \beta F_{\mathrm{A}} I_{0}(\phi \Sigma \mu)$, where $e$ is the elementary charge, $\beta=2.2$ is the geometric factor for the X-band waveguide used, $I_{0}$ is the incident photon flux, $F_{\mathrm{A}}$ the fraction of light absorbed at the excitation wavelength, $\phi$ is the quantum efficiency of free carrier generation per photon absorbed and $\Sigma \mu=\mu_{\mathrm{e}}+\mu_{\mathrm{h}}$ the sum of the mobilities of electrons and holes. Bi-exponential fits of the photoconductivity decay transients were weighted to calculate the average carrier lifetime using the equation: $\tau_{\text {avg }}=$ $\left(A_{0} \tau_{0}+A_{1} \tau_{1}\right) /\left(A_{0}+A_{1}\right)$. For a charge-carrier yield of $f=1$, the combined charge carrier mobility at $t=0$ can be derived from the sum of the pre-exponential factors $(\Sigma A)$ of the fits.

Capacitance-voltage measurement: Capacitance-voltage measurement was conducted with an Agilent E4980A LCR meter. The carrier concentration $n$ can be derived from the equation $n=\frac{2}{q \varepsilon A^{2} d\left(1 / C^{2}\right) / d V}$, where $n, q, \varepsilon, A, C$ and $V$ are carrier concentration, element charge, dielectric constant, device area, capacitance and applied voltage, respectively.

Optical simulations: The thickness at $90 \%$ absorption in Fig. 1a is derived from another format of Beer-Lambert law $\ell=-\ln 10 \times(\lg T) / a$, where $T$ and $a$ is the transmittance and absorption coefficient. A Matlab program based on transfer matrix method was used for optical simulations in Fig. $1 b^{38}$. Theoretical photocurrent in optical simulation is obtained assuming $90 \%$ EQE for both WBG and NBG perovskites in absorbing region.

Other characterizations: The SEM images were taken from a Hitachi S- 4700 Cold Cathode Field Emission Scanning Electron Microscope. Light-intensitydependent measurements for ideality factors were measured with a series of neutral optical density filters. Film thicknesses were measured by a Bruker DektakXT stylus profiler. PL spectra were measured with a Horiba iHR320 Imaging Spectrometer. X-ray diffraction (XRD) patterns were measured with a Rigaku Miniflex 6GBenchtop XRD system. UV-vis absorbance is measured with Evolution ${ }^{\text {ix }} 201$ UV-Visible Spectrophotometers. XPS is conducted by Kratos Axis Ultra DLD Xray Photoelectron Spectrometer with a monochromatic $\mathrm{Al} \mathrm{K}$ alpha source for highenergy resolution work.

Reporting summary. Further information on research design is available in the Nature Research Reporting Summary linked to this article.

\section{Data availability}

The data that support the findings of this study are available from the corresponding author upon reasonable request.

Received: 15 July 2019; Accepted: 10 September 2019; Published online: 03 October 2019

\section{References}

1. Best Research-Cell Efficiencies Chart-NREL. https://www.nrel.gov/pv/cellefficiency.html (2019).

2. Kojima, A., Teshima, K., Shirai, Y. \& Miyasaka, T. Organometal halide perovskites as visible-light sensitizers for photovoltaic cells. J. Am. Chem. Soc 131, 6050-6051 (2009).

3. Tan, H. et al. Efficient and stable solution-processed planar perovskite solar cells via contact passivation. Science 355, 722-726 (2017).

4. Saliba, M. et al. Incorporation of rubidium cations into perovskite solar cells improves photovoltaic performance. Science 354, 206-209 (2016).

5. Lee, M. M., Teuscher, J., Miyasaka, T., Murakami, T. N. \& Snaith, H. J. Efficient hybrid solar cells based on meso-superstructured organometal halide perovskites. Science 338, 643-647 (2012).

6. Jiang, Q. et al. Planar-structure perovskite solar cells with efficiency beyond 21\%. Adv. Mater. 29, 1703852 (2017).

7. Jeon, N. J. et al. A fluorene-terminated hole-transporting material for highly efficient and stable perovskite solar cells. Nat. Energy 3, 682-689 (2018).

8. Shockley, W. \& Queisser, H. J. Detailed balance limit of efficiency of p-n junction solar cells. J. Appl. Phys. 32, 510-519 (1961).

9. Hao, F., Stoumpos, C. C., Cao, D. H., Chang, R. P. H. \& Kanatzidis, M. G. Lead-free solid-state organic-inorganic halide perovskite solar cells. Nat. Photonics 8, 489 (2014).

10. Noh, J. H., Im, S. H., Heo, J. H., Mandal, T. N. \& Seok, S. I. Chemical management for colorful, efficient, and stable inorganic-organic hybrid nanostructured solar cells. Nano Lett. 13, 1764-1769 (2013).

11. Eperon, G. E. et al. Formamidinium lead trihalide: a broadly tunable perovskite for efficient planar heterojunction solar cells. Energy Environ. Sci. 7, 982-988 (2014).

12. Sahli, F. et al. Fully textured monolithic perovskite/silicon tandem solar cells with $25.2 \%$ power conversion efficiency. Nat. Mater. 17, 820-826 (2018).

13. Bush, K. A. et al. $23.6 \%$-efficient monolithic perovskite/silicon tandem solar cells with improved stability. Nat. Energy 2, 17009 (2017).

14. Chen, B. et al. Grain engineering for perovskite/silicon monolithic tandem solar cells with efficiency of 25.4\%. Joule 3, 177-190 (2019).

15. Han, Q. et al. High-performance perovskite/ $\mathrm{Cu}(\mathrm{In}, \mathrm{Ga}) \mathrm{Se}_{2}$ monolithic tandem solar cells. Science 361, 904-908 (2018)

16. Fu, F. et al. High-efficiency inverted semi-transparent planar perovskite solar cells in substrate configuration. Nat. Energy 2, 16190 (2016).

17. Chen, C.-C. et al. Perovskite/polymer monolithic hybrid tandem solar cells utilizing a low-temperature, full solution process. Mater. Horiz. 2, 203-211 (2015).

18. Todorov, T., Gershon, T., Gunawan, O., Sturdevant, C. \& Guha, S. Perovskitekesterite monolithic tandem solar cells with high open-circuit voltage. Appl. Phys. Lett. 105, 173902 (2014).

19. Eperon, G. E. et al. Perovskite-perovskite tandem photovoltaics with optimized band gaps. Science 354, 861-865 (2016).

20. Forgács, D. et al. Efficient monolithic perovskite/perovskite tandem solar cells. Adv. Energy Mater. 7, 1602121 (2017).

21. Rajagopal, A. et al. Highly efficient perovskite-perovskite tandem solar cells reaching $80 \%$ of the theoretical limit in photovoltage. Adv. Mater. 29, 1702140 (2017). 
22. Leijtens, T. et al. Tin-lead halide perovskites with improved thermal and air stability for efficient all-perovskite tandem solar cells. Sustain. Energy Fuels 2, 2450-2459 (2018).

23. Zhao, D. et al. Efficient two-terminal all-perovskite tandem solar cells enabled by high-quality low-bandgap absorber layers. Nat. Energy 3, 1093-1100 (2018).

24. Yang, Z. et al. Stable low-bandgap $\mathrm{Pb}-\mathrm{Sn}$ binary perovskites for tandem solar cells. Adv. Mater. 28, 8990-8997 (2016).

25. Zhao, D. et al. Four-terminal all-perovskite tandem solar cells achieving power conversion efficiencies exceeding 23\%. ACS Energy Lett. 3, 305-306 (2018).

26. Chung, I. et al. CsSnI3: semiconductor or metal? high electrical conductivity and strong near-infrared photoluminescence from a single material. high hole mobility and phase-transitions. J. Am. Chem. Soc. 134, 8579-8587 (2012).

27. Ma, L. et al. Carrier diffusion lengths of over $500 \mathrm{~nm}$ in lead-free perovskite CH3NH3SnI3 films. J. Am. Chem. Soc. 138, 14750-14755 (2016).

28. Yang, Z., Rajagopal, A. \& Jen, A. K. Y. Ideal bandgap organic-inorganic hybrid perovskite solar cells. Adv. Mater. 29, 1704418 (2017).

29. Noel, N. K. et al. Lead-free organic-inorganic tin halide perovskites for photovoltaic applications. Energy Environ. Sci. 7, 3061-3068 (2014).

30. Kumar, M. H. et al. Lead-free halide perovskite solar cells with high photocurrents realized through vacancy modulation. Adv. Mater. 26, 7122-7127 (2014).

31. Rajagopal, A., Liang, P.-W., Chueh, C.-C., Yang, Z. \& Jen, A. K. Y. Defect passivation via a graded fullerene heterojunction in low-bandgap $\mathrm{Pb}$ - $\mathrm{Sn}$ binary perovskite photovoltaics. ACS Energy Lett. 2, 2531-2539 (2017).

32. Zhao, D. et al. Low-bandgap mixed tin-lead iodide perovskite absorbers with long carrier lifetimes for all-perovskite tandem solar cells. Nat. Energy 2, 17018 (2017).

33. Shen, L. et al. A self-powered, sub-nanosecond-response solution-processed hybrid perovskite photodetector for time-resolved photoluminescence-lifetime detection. Adv. Mater. 28, 10794-10800 (2016).

34. Tong, J. et al. Carrier lifetimes of $>1 \mu \mathrm{s}$ in $\mathrm{Sn}-\mathrm{Pb}$ perovskites enable efficient all-perovskite tandem solar cells. Science 364, 475-479 (2019).

35. Saidaminov, M. I. et al. Suppression of atomic vacancies via incorporation of isovalent small ions to increase the stability of halide perovskite solar cells in ambient air. Nat. Energy 3, 648-654 (2018).

36. Ashburn, P., Morgan, D. V. \& Howes, M. J. A theoretical and experimental study of recombination in silicon $\mathrm{p}-\mathrm{n}$ junctions. Solid-State Electron. 18, 569-577 (1975).

37. Zheng, X. et al. Defect passivation in hybrid perovskite solar cells using quaternary ammonium halide anions and cations. Nat. Energy 2, 17102 (2017).

38. Katsidis, C. C. \& Siapkas, D. I. General transfer-matrix method for optical multilayer systems with coherent, partially coherent, and incoherent interference. Appl. Opt. 41, 3978-3987 (2002).

\section{Acknowledgements}

The information, data or work presented herein is funded by the U.S. Department of Energy, Office of Energy Efficiency and Renewable Energy, under award number DEEE0006709, and by the UNC Research Opportunities Initiative through the Center of
Hybrid Materials Enabled Electronic Technology. We acknowledge support for the transient absorption and microwave conductivity measurements from the Center for Hybrid Organic Inorganic Semiconductors for Energy (CHOISE), an Energy Frontier Research Center funded by the DOE Office of Basic Energy Sciences, Office of Science. Work at NREL was conducted through contract DE-AC36-08GO28308 with DOE. J. J. B. thanks the financial support from the U.S. Office of Naval Research.

\section{Author contributions}

J. H. conceived the idea, J.H., Z.Ya. and H.W. designed the experiments. Z.Ya. fabricated and optimized the NBG and tandem solar cells and conducted the characterization. Z.Yu. optimized the WBG PSCs. X.X. measured the TPC. Y.D. performed the laser scribing. B.C. optimized the ITO sputtering and connect the circuit of long-term stability of cells B.C. and P.R. conducted the SEM. Z.N. and Z.Ya. measured the $t$ DOS, S.H. and J.B. measured and analyzed the TRMC, X.C., K.W. and M.B. performed and analyzed TA. J.Z. conducted the XRD measurement. J.H. and Z.Ya. wrote the paper, and all authors reviewed the paper.

\section{Competing interests}

The authors declare no competing interests.

\section{Additional information}

Supplementary information is available for this paper at https://doi.org/10.1038/s41467019-12513-x.

Correspondence and requests for materials should be addressed to J.H.

Peer review information Nature Communications thanks the anonymous reviewer(s) for their contribution to the peer review of this work.

Reprints and permission information is available at http://www.nature.com/reprints

Publisher's note Springer Nature remains neutral with regard to jurisdictional claims in published maps and institutional affiliations.

\begin{abstract}
(c) (i) Open Access This article is licensed under a Creative Commons Attribution 4.0 International License, which permits use, sharing, adaptation, distribution and reproduction in any medium or format, as long as you give appropriate credit to the original author(s) and the source, provide a link to the Creative Commons license, and indicate if changes were made. The images or other third party material in this article are included in the article's Creative Commons license, unless indicated otherwise in a credit line to the material. If material is not included in the article's Creative Commons license and your intended use is not permitted by statutory regulation or exceeds the permitted use, you will need to obtain permission directly from the copyright holder. To view a copy of this license, visit http://creativecommons.org/ licenses/by/4.0/.
\end{abstract}

(c) The Author(s) 2019 